\title{
miR-377 targets CUL4A and regulates metastatic capability in ovarian cancer
}

\author{
RUFEN YU ${ }^{1}$, LIMEI CAI $^{1}$, YINGUI CHI ${ }^{1}$, XIANGCUI DING ${ }^{1}$ and XUEQING WU ${ }^{2}$ \\ ${ }^{1}$ Department of Obstetrics and Gynecology, Ruian People's Hospital, The Third Affiliated Hospital of Wenzhou Medical University, \\ Wenzhou, Zhejiang 325200; ${ }^{2}$ Department of Obstetrics and Gynecology, The First Affiliated Hospital of Wenzhou Medical University, \\ The First Provincial Wenzhou Hospital of Zhejiang, Wenzhou, Zhejiang 325000, P. R. China
}

Received May 17, 2017; Accepted January 31, 2018

DOI: $10.3892 /$ ijmm.2018.3540

\begin{abstract}
The incidence and recurrence rates of ovarian cancer are still high, and once the disease metastasizes, it is nearly always fatal. Cullin 4A (CUL4A) serves a significant role in tumourigenesis and tumour progression; however, the effect and mechanisms underlying CUL4A overexpression are still unknown. The role of microRNAs (miRs) in the regulation of metastatic capability in ovarian cancer cell lines was investigated. The interaction between miR-377 and CUL4A was investigated using bioinformatics analyses and dual-luciferase reporter assays. Furthermore, miR-377 mRNA and protein levels were detected using reverse transcription-quantitative polymerase chain reaction and western blotting, respectively and cell migration and invasion were detected using a Transwell assay. Results revealed that CUL4A expression was negatively associated with miR-377 levels in ovarian cancer tissues and cell lines. Through in silico analysis, the targeting effect of miR-377 on CUL4A was verified. Ectopic expression of miR-377 in SKOV3 cells downregulated the level of CUL4A, and significantly reduced the migratory ability of the cells. miR-377 overexpression led to reduced activity of the $\mathrm{Wnt} / \beta$-catenin signaling pathway, and regulated the expression of matrix metalloproteinase-2, and 9, and epithelial-mesenchymal transition (EMT)-associated protein. These results suggested that miR-377 is a significant negative regulator of CUL4A that controls cancer cell progression in ovarian cancer cell lines.
\end{abstract}

\section{Introduction}

According to a previous study, ovarian cancer still remains the fifth-leading cause of mortality in women, with approximately

Correspondence to: Mr. Yingui Chi, Department of Obstetrics and Gynecology, Ruian People's Hospital, The Third Affiliated Hospital of Wenzhou Medical University, 108 Wansong Road, Ruian, Wenzhou, Zhejiang 325200, P.R. China

E-mail: yinguichi@163.com

Key words: miRNA-377, cullin 4A, ovarian cancer, cell proliferation tumour metastasis
22,280 newly diagnosed cases and 14,240 mortalities reported in 2016 worldwide (1). With such a high recurrence rate, over three quarters of ovarian cancer patients eventually relapse following primary platinum and taxane-based chemotherapy (2). Development of cytotoxic chemotherapy and novel targeted therapies have enhanced progression-free survival, however failed to have significant influence on overall survival $(3,4)$. Malignant tumours, including ovarian cancer, are characterized by tumour metastasis from the primary site to other parts via the lymphatic system, blood vessels, or body cavity (5). To better understand the underlying molecular mechanism of carcinogenesis in order to develop more effective therapeutic strategies, more research studies need to be conducted.

Previously, the use of miRNAs as a novel effective target in cancer therapy has been extensively reported (6-10). miRNAs are small non-coding RNA molecules with a length varying from 19-25 nt. Previous studies have demonstrated that miRNAs that are generated in cells serve important roles in a variety of biological processes; in particular, they negatively regulate gene expression following transcription. A mature miRNA chain is able to combine with the $3^{\prime}$ untranslated region (UTR) of target mRNA in an RNA-induced silencing complex; in this way, complete complementary miRNA and target mRNA result in inhibition or activation of translation of the mRNA (11-13). miRNAs take part in various physiological processes, including cell proliferation, differentiation, and apoptosis, by regulating transcription of their target genes. In neoplastic processes, aberrantly expressed miRNAs affect proliferation, migration, and invasion of cancer cells by mediating associated proteins or transcription factors so as to exert promotive or inhibitory effects on tumorigenesis and metastasis (14-16). Several lines of evidence have verified that miRNAs may directly or indirectly control oncogenes or suppressor genes to mediate protein expression of cancer-associated pathways $(17,18)$. Based on previous studies, miR-377, a member of the large miRNA cluster on chromosome $14 q 32$, is weakly expressed in several human malignancies, including ependymoma, osteosarcoma, neuroblastoma, gastro-intestinal stromal tumours, and gliomas (6-10). To the best of the author's knowledge, there is a lack of information about the association between miR-377 and ovarian cancer; thus, the present study investigated whether miR-377 serves 
an important role in the control of proliferation and metastasis in ovarian cancer, and in particular, if it exhibits inhibitory capabilities.

Cullin (CUL) 4A, which was demonstrated to be one of the target genes of miR-377 in the present study, belongs to the family of Cullin-Ring E3-ligases (CRLs) and serves a key role in tumorigenesis and tumor progression (19). CUL4A constitutes a helical $\mathrm{N}$-terminal domain and a spherical C-terminal domain which combine with Ras like without CAAX 1 (RIT1) and damage specific DNA binding protein 1, respectively (20). CUL4A, initially reported in breast cancer, was previously demonstrated overexpressed in numerous cancers, including squamous-cell carcinoma, adrenocortical carcinoma, medulloblastoma and liver cancer (21). Overexpression of CUL4A leads to promotion of cancer cell proliferation, and is closely and positively associated with overall survival and disease-free survival of cancer patients (22). The present study focused on the role of miR-377 in the control of CUL4A expression in ovarian cancer cell lines.

\section{Materials and methods}

Tumor samples. A total of 44 ovarian cancer patients in the Third Affiliated Hospital of Wenzhou Medical University were included in the present study. During the period from February 2015 to March 2016, all cancer specimens were obtained from surgical tumor resections, and their adjacent normal ovarian tissue specimens were collected at the same time, as negative controls. The normal and cancer tissues represented matched pairs from each patient. Basic clinical and pathological data of these patients at the average age of $51.12 \pm 16.35$ were collected with their written informed consent forms. The present study was approved by the ethics committee of the Third Affiliated Hospital of Wenzhou Medical University (Wenzhou, China).

Cell culture and grouping. Normal ovary cell line (IOSE80) and seven ovarian cancer cells lines including CAOV3, SKOV3, A2780, OVCAR3, HO-8901, 3AO and TC-1 were all obtained from Shanghai Bogoo Biotechnology Co. Ltd. (Shanghai, China). Cells were cultured in Dulbecco's modified Eagle's medium (DMEM) supplemented with $10 \%$ fetal calf serum (Thermo Fisher Scientific Inc, Waltham, MA, USA) at $37^{\circ} \mathrm{C}$ in $5 \% \mathrm{CO}_{2}$ incubator. Medium was replaced once every two days. Cell passage cultivation was performed when cells grew to $90 \%$ confluency.

One cell line from six ovarian cancer cell lines was selected based on the expression of the miR-377 and CUL4A levels for the primary in vitro experiments of the effects of miR-377 on CUL4A in ovarian cancer in the present study. Cells were randomly allocated into three groups: Control group, mock group (cells transfected with blank plasmids) and mimics (cells transfected with miR-377 mimics). Recombinant plasmids were purchased by Nanjing Cobioer Biotechnology Co. Ltd. (Jiangsu, China). A total of $500 \mathrm{ng} / \mu \mathrm{l}$ plasmids were prepared. Transfection processes were carried out using Lipofectamine ${ }^{\circledR} 2000$ reagent (Thermo Fisher Scientific Inc.) according to the manufacturer's protocol. Prior to subsequent experimentation, transfected cells were incubated at $37^{\circ} \mathrm{C}$ in a $5 \% \mathrm{CO}_{2}$ incubator for $48 \mathrm{~h}$.
Bioinformatics analysis. To analyze the role of miRNA-377 in ovarian cancer, prediction of its target genes was carried out using the prediction software miRanda (www.microrna. org/microrna/home.do), miRDB (www.mirdb.org/), PicTar (pictar.mdc-berlin.de/) and TargetScan (www.targetscan. org/vert_71/) and the function of miRNA-377 was analyzed through the Database for Annotation, Visualization and Integrated Discovery (www.david.ncifcrf.gov/).

Luciferase reporter assay. CUL4A 3'-UTR and mutated CUL4A 3'-UTR were prepared by GeneCopoeia Inc. (Rockville, MD, USA). The 3'-UTR fragment of CUL4A with the binding site for miR-377 mimic and inhibitor was amplified via polymerase chain reaction (PCR) with the primer sequences presented in Table I and cloned into luciferase vectors (Promega Corporation, Madison, WI, USA). SKOV3 cells were seeded into 96-well plates at the density of $1 \times 10^{5}$ cells per well one day prior to transfection. Control luciferase reporter plasmid, CUL4A 3'-UTR and mutated CUL4A 3'-UTR were co-transfected with either miR-377 mimic or miR-377 inhibitor using Lipofectamine ${ }^{\circledR} 3000$ (Thermo Fisher Scientific Inc., USA). A total of $48 \mathrm{~h}$ following transfection, luciferase activity was determined with Secret-Pair ${ }^{\mathrm{TM}}$ Dual-Luciferase Reporter Assay (GeneCopoeia Inc.). The results were normalized through comparison with Renilla luciferase activity.

Cell Counting Kit (CCK)-8 assay. Cell viability in control, mock, and mimic groups was measured using the CCK- 8 assay (Beyotime Institute of Biotechnology, Shanghai, China). Cells were seeded into a 96-well plate $(100 \mu \mathrm{l} /$ well $)$, and cultured at $37^{\circ} \mathrm{C}$ in a $5 \% \mathrm{CO}_{2}$ incubator. A total of four hours following incubation, $10 \mu \mathrm{l}$ CCK-8 reagent was added to each well and incubated for 1-4 h. Optical density values were read by a iMark microplate absorbance reader (Bio-Rad Laboratories, Inc., Hercules, CA, USA) at a wavelength of $450 \mathrm{~nm}$.

Transwell assay. SKOV3 cells $\left(5 \times 10^{5}\right.$ cells $\left./ \mathrm{ml}\right)$ were seeded in the upper well of a Transwell migration system on ThinCerts ${ }^{\mathrm{TM}}$ inserts with 8- $\mu \mathrm{m}$ membranes (Huayue ReaCon Inc., Guangdong, China) in DMEM supplemented with $0.1 \%$ fetal bovine serum (FBS). The lower wells received the same medium supplemented with $10 \%$ FBS. Following a $24-h$ incubation period, the contents of the upper wells, which contained non-migrating cells were removed by cotton swabs. For invasion detection, the upper chambers were specifically coated with Matrigel. Cells that migrated or invaded through the membranes were fixated with $70 \%$ cold ethanol, stained with $0.1 \%$ crystal violet for $20 \mathrm{~min}$ at room temperature, and imaged using a light microscope (Olympus Corporation, Tokyo, Japan). The quantity of migrated cells was analysed from five randomly selected fields under the light microscope at a magnification of x100.

Reverse transcription-quantitative $(R T-q) P C R$. Quantification of miR-377 was carried out using TaqMan miRNAs assay (Thermo Fisher Scientific Inc). The PCR conditions included activating the DNA polymerase at $95^{\circ} \mathrm{C}$ for $15 \mathrm{~min}$, followed by 40 cycles of three-step PCR $\left(94^{\circ} \mathrm{C}\right.$ for $15 \mathrm{sec}, 55^{\circ} \mathrm{C}$ for $30 \mathrm{sec}$, and $70^{\circ} \mathrm{C}$ for $\left.30 \mathrm{sec}\right)$. Reverse transcription of $10 \mathrm{ng}$ template RNA was performed with a TaqMan MicroRNA 
Table I. Sequence of miR-377 mimics and inhibitor.

\begin{tabular}{|c|c|c|}
\hline Name & Direction & Sequence $\left(5^{\prime}-3^{\prime}\right)$ \\
\hline \multirow[t]{2}{*}{ miR-377 mimics } & Forward & $\begin{array}{l}\text { TGCTGATCACACAAAGGCAACTTTTGTGTTTTGGCCACTGACT } \\
\text { GACACAAAAGTCCTTTGTGTGAT }\end{array}$ \\
\hline & Reverse & $\begin{array}{l}\text { CCTGTAGTGTGTTTCCGTTGAAAACACAAAACCGGTG } \\
\text { ACTGACTGTGTTTTCAGGAAACACACTA }\end{array}$ \\
\hline \multirow[t]{2}{*}{ miR-377 inhibitor } & Forward & $\begin{array}{l}\text { TGCTGGGAAGTCATACAATCCTACA } \\
\text { TTGTTTTGGCCACTGACTGACAATGTAGGTGTATGACTTCC }\end{array}$ \\
\hline & Reverse & $\begin{array}{l}\text { CCTGCCTTCAGTATGTTAGGATGTAACAA } \\
\text { AACCGGTGACTGACTGTTACATCCACATACTGAAGG }\end{array}$ \\
\hline miR-377 UTR & & AUCACACAAAGGCAACUUUUGU \\
\hline CUL4A UTR & & UGGUUUGUU-CUCGUGUGUGAU \\
\hline
\end{tabular}

miR, microRNA; UTR, untranslated region; CUL, cullin.

Table II. Association between CUL4A and clinical data of ovarian cancer patients.

\begin{tabular}{lcc}
\hline Cancer stage & Age $(<45 / \geq 45)$ & $\begin{array}{c}\text { CUL4A expression } \\
\text { (low/high) }\end{array}$ \\
\hline TNM & & \\
I & $6 / 8$ & $9 / 5$ \\
II & $4 / 8$ & $3 / 9$ \\
III & $7 / 11$ & $4 / 14$ \\
P-value & 0.883 & $0.031^{\mathrm{a}}$ \\
\hline
\end{tabular}

${ }^{\mathrm{a}} \mathrm{P}<0.05$, Chi-square test; CUL, cullin.

Reverse Transcription kit and miRNA-specific stem-loop primers (Table I). The expression of miR-377 was normalized to U6 expression. The $2^{-\Delta \Delta \mathrm{Cq}}$ method was performed for the quantification of gene expression data (23).

To determine mRNA levels of CUL4A, $\beta$-catenin, Wnt3a, cyclin D1, matrix metalloproteinases (MMP)-2 and -9, metastasis-associated protein (MTA)-1, and metallopeptidase inhibitor (TIMP), total RNA was firstly reverse transcribed using the Takara PrimeScript RT reagent kit (Takara Bio, Inc., Otsu, Japan). Quantification of mRNA was carried out by TaqMan Gene Expression Assay (Thermo Fisher Scientific Inc, USA). PCR was carried out by activating the DNA polymerase at $95^{\circ} \mathrm{C}$ for $10 \mathrm{~min}$, followed by 40 cycles of two-step PCR $\left(95^{\circ} \mathrm{C}\right.$ for $15 \mathrm{sec}$ and $60^{\circ} \mathrm{C}$ for $\left.45 \mathrm{sec}\right)$. Target gene expression was normalized to GAPDH expression. Primer sequences were listed as follows: CUL4A forward, 5'CAAGAACTT CCGAGACAGACC3' and reverse, 5'TGCTTGTAGAGCATT GGGGA3'; $\beta$-catenin forward, 5'TATAAGAGCTCCTTG TGCGGC3' and reverse, 5'CTGAAGCTGCTCCTCAGA CC3'; Wnt3a forward, 5'CTGGAGCTAGTGTCTCCTCTCT3' and reverse, 5'GGAAGAAGCCTCATCCACCA3'; cyclin D1 forward, 5'CAATGACCCCGCACGATTTC3' and reverse, 5'AAGTTGTTGGGGCTCCTCAG3'; MMP-2 forward, 5'TGT GTTGTCCAGAGGCAATG3' and reverse, 5'ATCACTAGG
CCAGCTGGTTG3'; MMP-9 forward, 5'TTTGAGTCCGGT GGACGATG3' and reverse, 5'GCTCCTCAAAGACCGAGT CC3'; MTA1 forward, 5'AAACTGCCCTGAGTGTGGT3' and reverse, 5'AAATATGTTGACCCAGCTCATCT3'; TIMP1 forward, 5'GCCTGACGGTCATATGGTAGA3' and reverse, 5'GAATGCGCCAAAAACCCCAT3' and GAPDH forward, 5'GAATGGGCAGCCGTTAGGAA3' and reverse, 5'AAA AGCATCACCCGGAGGAG3'. The $2^{-\Delta \Delta C q}$ method was performed for the quantification of gene expression data (23).

Western blot analysis. Total protein of cells in each group was extracted using the ProteoPrep ${ }^{\circledR}$ Total Extraction Sample kit (Sigma-Aldrich; Merck KGaA, Darmstadt, Germany). Cell lysates were prepared with the cell lysis buffer (Beyotime Institute of Biotechnology). Following centrifugation $(12,000 \mathrm{x} \mathrm{g})$ at $4^{\circ} \mathrm{C}$ for $10 \mathrm{~min}$, the supernatant was collected. Concentration of the protein was determined by Bradford assay (Bio-Rad Laboratories, Inc.). A total of $30 \mathrm{mg}$ of each protein sample were separated on 10-15\% SDS-PAGE (Merck KGaA, Darmstadt, Germany). The membranes were blocked using 5\% fat-free milk in TBST at room temperature for $1 \mathrm{~h}$. Membranes were incubated with primary antibodies at $4^{\circ} \mathrm{C}$ for $6 \mathrm{~h}$ and then at room temperature for $4 \mathrm{~h}$. The primary specific antibodies used were anti-CUL4A (catalog no. ab72548; 1:1,000; Abcam, Cambridge, MA, USA), anti- $\beta$-catenin (catalog no. ab32572; 1:5,000; Abcam), anti-Wnt3a (catalog no. ab19925; 1:1,000; Abcam), anti-cyclin D1 (catalog no. ab134175; 1:10,000; Abcam), anti-MMP2 (catalog no. ab92536; 1:1,000; Abcam), anti-MMP9 (catalog no. ab38898; 1:1,000; Abcam), anti-MTA1 (catalog no. ab71153; 1:2,000; Abcam) and anti-GAPDH (catalog no. ab8245, 1:2,000; Abcam). The membranes were incubated with the following secondary antibodies at room temperature for $1 \mathrm{~h}$ : Goat anti-mouse IgG H\&L (catalog no. ab6789; 1:2,000; Abcam), goat anti-rabbit IgG H\&L (catalog no. ab6721; 1:2,000; Abcam) and donkey anti-goat IgG H\&L (catalog no. ab6885; 1:2,000; Abcam). Blots were visualized using enhanced chemiluminescence (Thermo Fisher Scientific, Inc.). Densitometry of the bands was performed using Quantity One software, version 4.6.9 (Bio-Rad Laboratories, Inc.). 

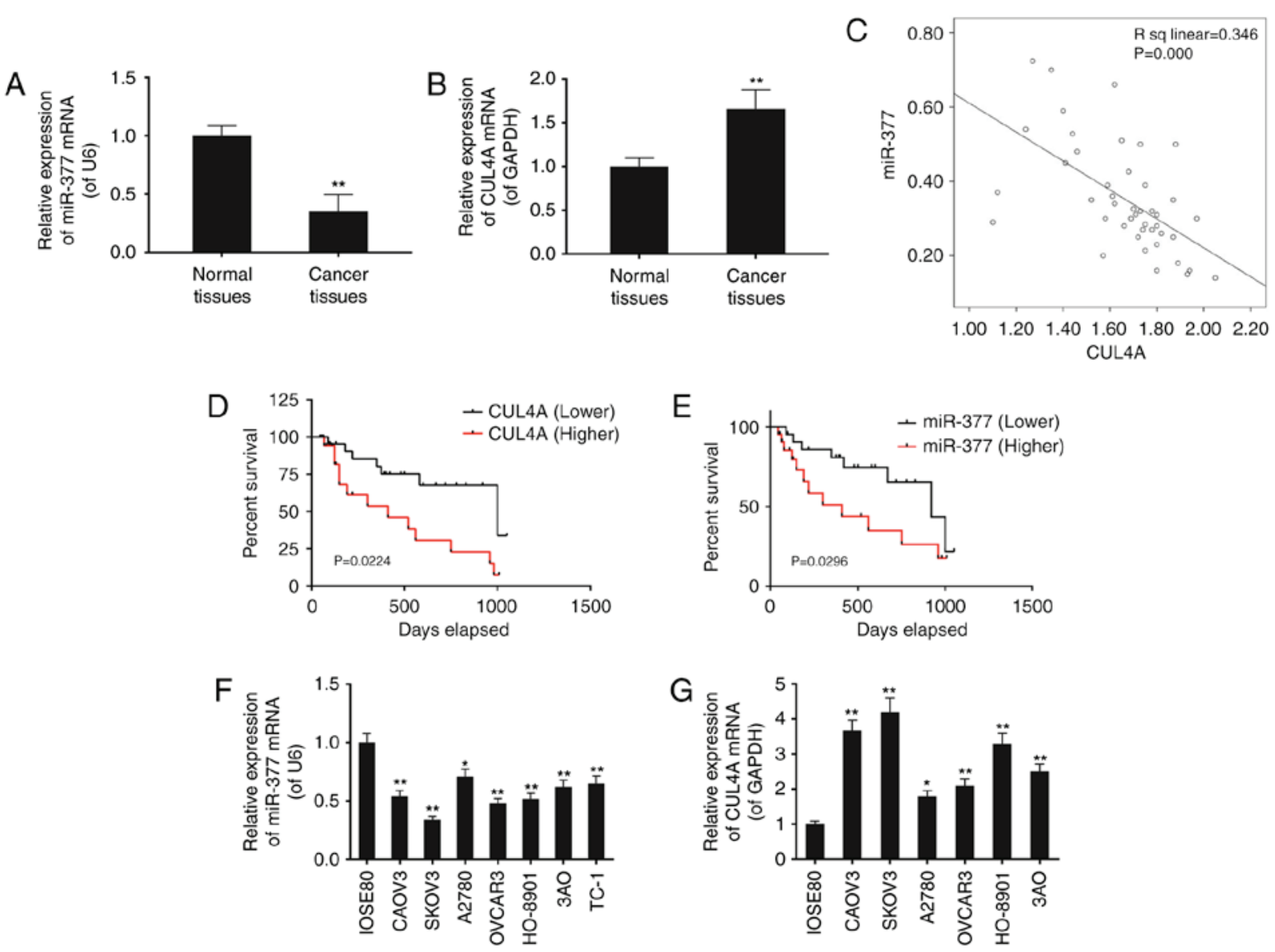

Figure 1. The expression levels of miR-377 and CUL4A in ovarian cancer tissues and cell lines (CAOV3, SKOV3, A2780, OVCAR3, HO-8901 and 3AO) were assessed. (A) miR-377 levels were decreased in cancer tissues compared with their adjacent normal tissues, whereas (B) mRNA levels of CUL4A were elevated. (C) Linear correlation of mRNA levels between miR-377 and CUL4A were assessed. Survival analysis demonstrated that ovarian cancer patients with (D) increased level of CUL4A and (E) decreased level of miR-377, lived shorter that the patients with decreased CUL4A and increased miR-377 expression level, respectively. (F) The miR-377 level was significantly lower in ovarian cancer cells compared with normal cells (IOSE80), whereas (G) mRNA levels of CUL4A were greater in ovarian cancer cells compared with normal cells (IOSE80). Data are expressed as the mean \pm standard deviation from three independent experiments. ${ }^{* *} \mathrm{P}<0.01$ vs. IOSE80 normal cells. CUL4, cullin 4A; miR, microRNA.

Statistical analysis. Statistical analysis was performed using SPSS software, version 22.0 (IBM Corp., Armonk, NY, USA). Each experiment was repeated three times, and data are presented as the mean \pm standard deviation. Student's t-test and one-way analysis of variance, followed by Tukey and Bonferroni post-hoc tests were used in either two or multiple group comparisons, for statistical significance. Spearman's nonparametric correlation test was used to analyze the correlations between the miR-377 and CUL4A mRNA levels in tissue samples. The Chi squared test was used for analysis of the significance of CUL4A to clinicopathological characteristics. The method of survival analysis was used for testing divided phases. $\mathrm{P}<0.05$ was considered to indicate a statistically significant difference.

\section{Results}

Expression levels of $m i R-377$ and CUL4A in ovarian cancer tissues and cell lines. The present study included a total of 44 patients at the average age of $51.12 \pm 16.35$ (Table II). The expression of miR-377 and CUL4A in surgically resected ovarian cancer specimens and adjacent normal ovarian tissues was assessed using RT-qPCR. Compared with the normal ovarian tissues, the levels of miR-377 in ovarian cancer specimens was decreased, and the expression of CUL4A was increased, and the correlation analysis indicated a negative correlation between miR-377 and CUL4A expression (Fig. 1A-C). It was also detected that the survival rate of ovarian cancer patients with decreased levels of CUL4A and increased miR-377 was greater compared with those that demonstrated the opposing trends $(\mathrm{P}<0.05$; Fig. 1D and $\mathrm{E})$.

Decreased miR-377 expression along with increased CUL4A expression was also detected in seven ovarian cancer cell lines including CAOV3, SKOV3, A2780, OVCAR3, HO-8901, 3AO and TC-1, compared with in the normal cell line IOSE80, however this difference was most evident in SKOV3 cells $(\mathrm{P}<0.05$; Fig. $1 \mathrm{~F}$ and $\mathrm{G})$.

Verification of CUL4A as the direct target of miR-377. In silico analysis of human miR-377 began with surveys of its target-prediction. A total of four prediction software programs; miRanda, miRDB, PicTar, and TargetScan, detected 3.812, 767,185 , and 4.920 target genes, respectively. Based on the result of the Venn diagram, a total of 52 reliable target genes of miR-377 were discovered through intersection calculation of predicted target genes from the four online programs (Fig. 2A). Subsequent gene ontology (GO) analysis of gene 
A

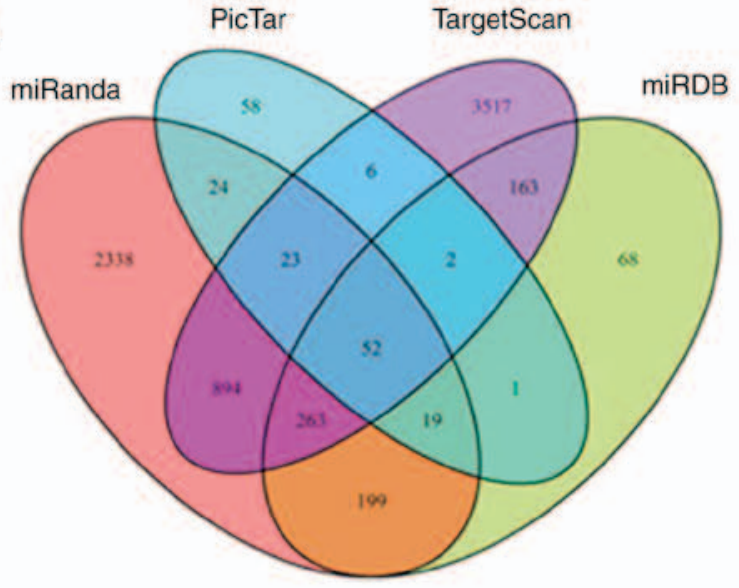

B GO:0045944-positive regulation of transcription fro51726-regulation of cell cycleGO:0045893-positive regulation of transcription, DNA-templatedGO-0045444-fat cell differentiationGO:0042921-glucocorticoid receptor signaling pathwayGO:0031464-Cul4A-RING E3 ubiquitin ligase complexGO:0031461-Cullin-RING ubiquitin ligase complexGO:0019899-enzyme bindingGO-0016032-viral processGO:0010837-regulation of keratinocyte proliferationGO:0008285-negative regulation of cell proliferation. GO:0007223-Wnt signaling pathway, calcium modulating pathwayGO:0007050-cell cycle arrestGO:0006396-ANA processingGO:0006351-transcription, DNA.templatedGO:0006351-transcription, DNA-templated-
GO:0006349 regulation of gene expression by genetic imprintingGO:0005737-cytoplasm. GO:0005730-nucleolusGO:0005654-nucleoplasmGO:0005634-nucleusGO:0005515 - protein binding. GO:0003729-mRNA binding-
GO:0003713-transcription coactivator activityGO:0003677-DNA binding. GO.0002223-stimulatory C-type lectin receptor signaling pathwayGO:0001570 vasculogenesisGO:0000932-cytoplasmic mRNA processing bodyGO:0000082 - G1/S transition of mitotic cell cycle-

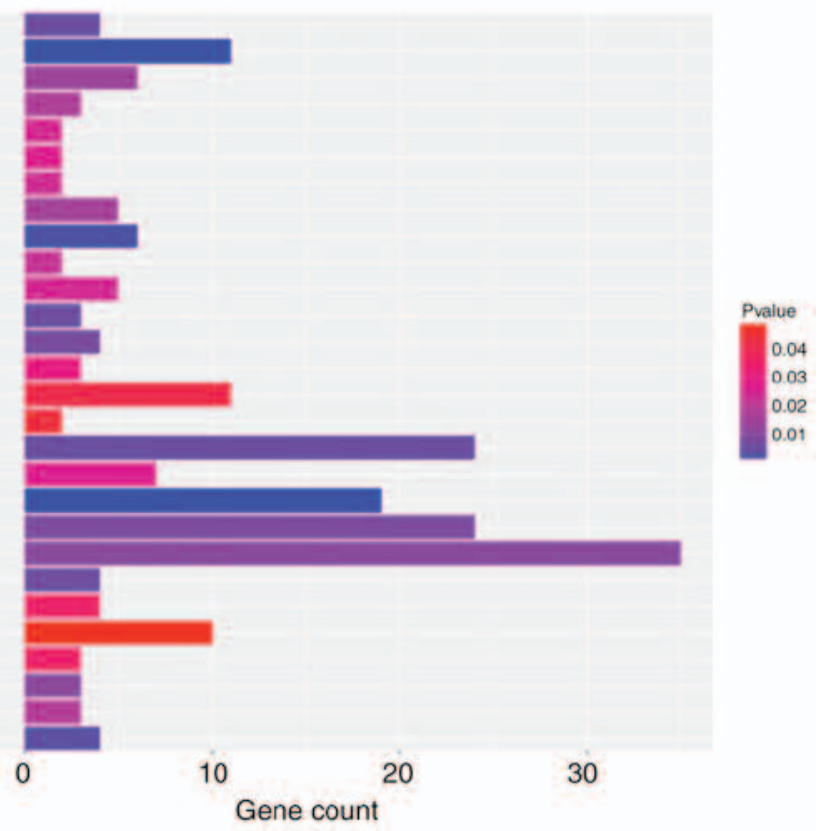

C Pre-miR-377

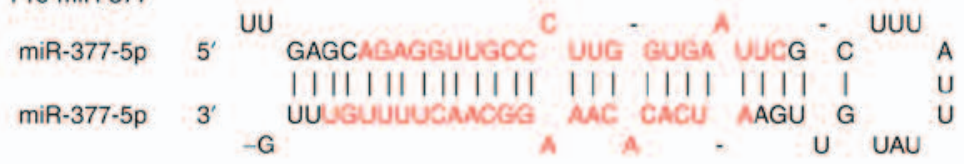

$D_{5}$

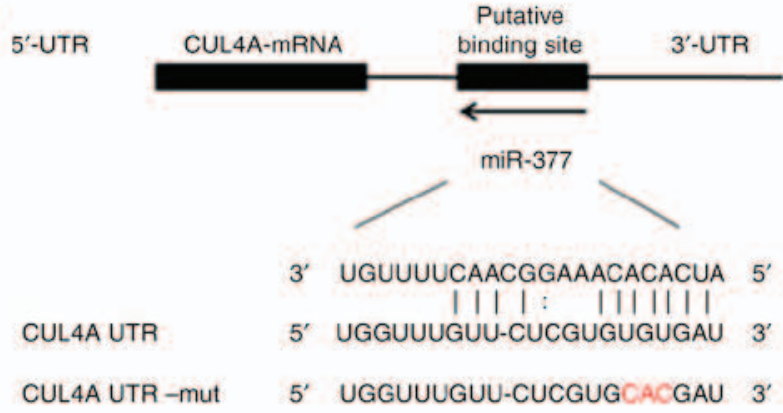

E

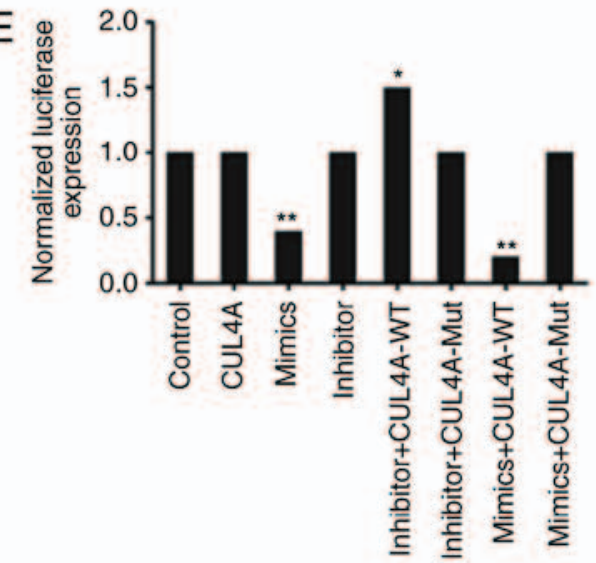

Figure 2. Target genes of miR-377 identified through bioinformatic and luciferase reporter analysis. (A) A total of 52 reliable target genes of miR-377 were discovered through intersection calculation of predicted target genes from miRanda, miRDB, PicTar and TargetScan. (B) Gene ontology analysis of gene function revealed 28 annotations of miR-377-associated biological processes, genes were enriched in processes of regulation of gene expression, cell proliferation and signal transduction. (C) Cervical-loop structures of pre-miR-377. (D) Mature hsa-miR-377 (miR-377) was predicted to interact with the CUL4-3' UTR from positions 319 to 349 via a 7-mer seed match interaction. (E) Relative luciferase activity demonstrated that miR-377 reduced luciferase reporter activity. Data are expressed as the mean \pm standard deviation from three independent experiments. ${ }^{*} \mathrm{P}<0.05$ and ${ }^{* *} \mathrm{P}<0.01$ vs. control. CUL4, cullin $4 \mathrm{~A}$; miR, microRNA; mut, mutant; WT, wild type; UTR, untranslated region. 


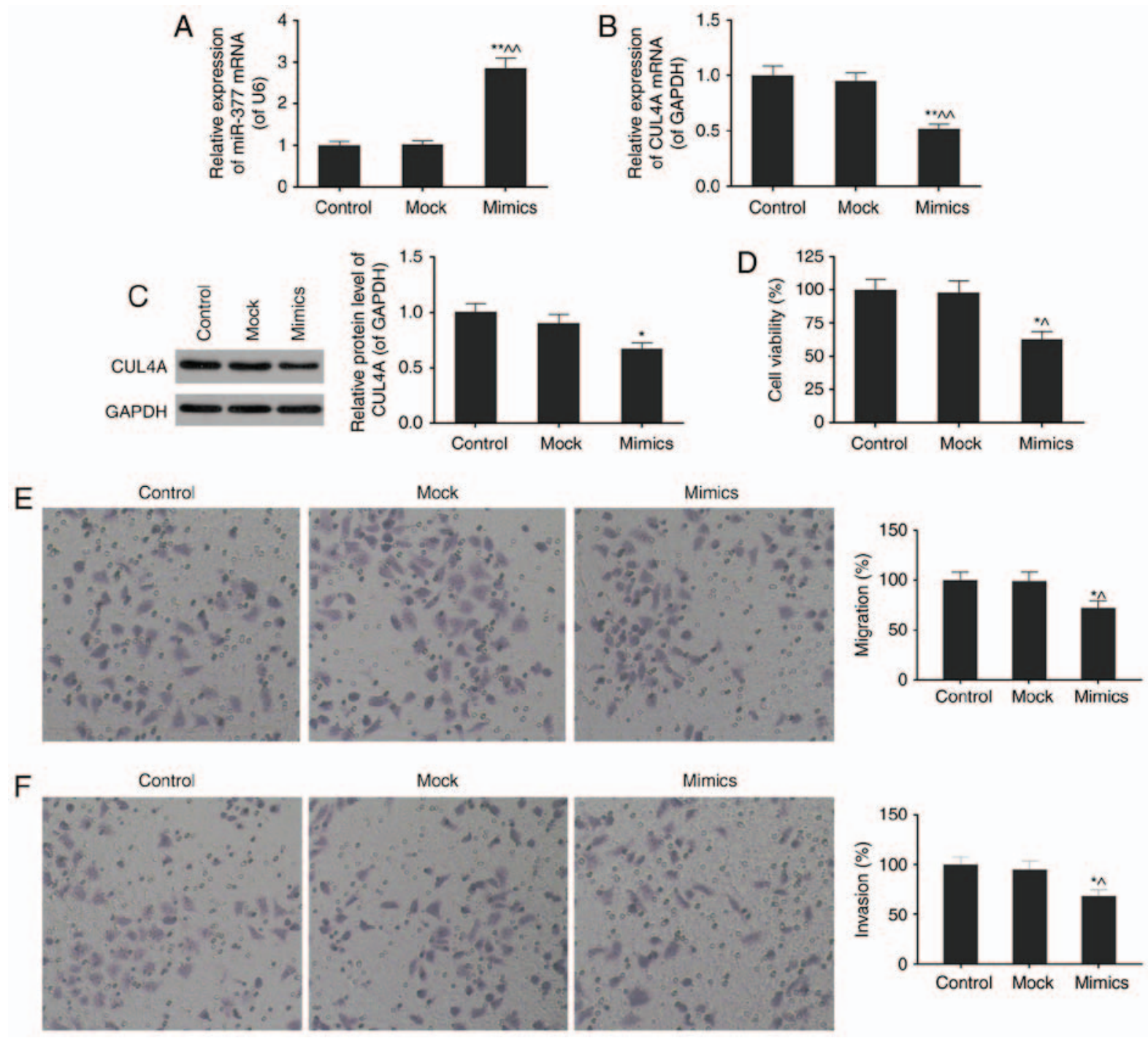

Figure 3. miR-377 overexpression affects cell viability, migration and invasion. (A) Ectopic miR-377 expression decreased the (B) CUL4A mRNA level. (C) The expression of CUL4A protein was inhibited by miR-377 mimics. (D) miR-377 overexpression decreased the viability of SKOV3 cells. miR-377 attenuated (E) cell migration and (F) cell invasion rates in SKOV3 cells (magnification, $\mathrm{x} 100$ ). Data are expressed as the mean \pm standard deviation from three independent experiments. ${ }^{*} \mathrm{P}<0.05$ and ${ }^{* *} \mathrm{P}<0.01$ vs. control, ${ }^{\wedge} \mathrm{P}<0.05$ and ${ }^{\wedge \wedge} \mathrm{P}<0.01$ vs. mock. CUL4, cullin $4 \mathrm{~A} ;$ miR, microRNA.

function revealed 28 annotations of biological processes which were associated with miR-377 $(\mathrm{P}<0.05)$. The target genes of miR-377 were primarily enriched during processes regulating gene expression, cell proliferation, and signal transduction (Fig. 2B).

Based on literature review, of the 52 predicted target genes, CUL4A was selected as it has been previously demonstrated to highly implicated in tumor progression and patient survival $(22,24)$. To investigate whether miR-377 is involved in the regulation of CUL4A protein expression, the alignment of miR-377/CUL4A was analysed (Fig. 2C). miR-377 is located in a miRNA cluster on chromosome 14q32.2. The stem-loop for miR-377 includes two different mature miRNA sequences, miR-377 (MIMAT0000730) from positions 45-66 and miR-377* (MIMAT0004689) from positions 7-28 (25). miR-377 was predicted to interact with a 7-mer seed match with the CUL4A-3' UTR from position 319-349 (Fig. 2D).

miR-377 interacts with CUL4A-3' UTR. A luciferase reporter involving the human CUL4A-3' UTR was applied to identify if miR-377 interacted directly with the CUL4A-3' UTR. Luciferase activity was tested $24 \mathrm{~h}$ following transfection of SKOV3 cells with the reporter miR-377 overexpression and inhibition constructs. In the assay system, a reduction in luciferase expression revealed a specific miR-377-3' UTR interaction. It was demonstrated that luciferase activity was significantly decreased in miR-377 overexpressed cells; in particular, in the miR-377 mimics + CUL4A-WT group, the luciferase expression was reduced to one fifth of the level in the control group $(\mathrm{P}<0.01$; Fig. $2 \mathrm{E})$. Mutation of the predicted binding sites in CUL4A-3' UTR eliminated this decrease in luciferase reporter activity. This result suggested that miR-377 is involved in the control of CUL4A expression.

miR-377 downregulates CUL4A mRNA and protein expression levels in SKOV3 cells. As presented in Fig. 1D and E, the differential expression of miR-377 and CUL4A in SKOV3 cell line compared with normal cells was the most significant of the six ovarian cancer cell lines. In the present study, SKOV3 was selected for subsequent experimentation to probe into 

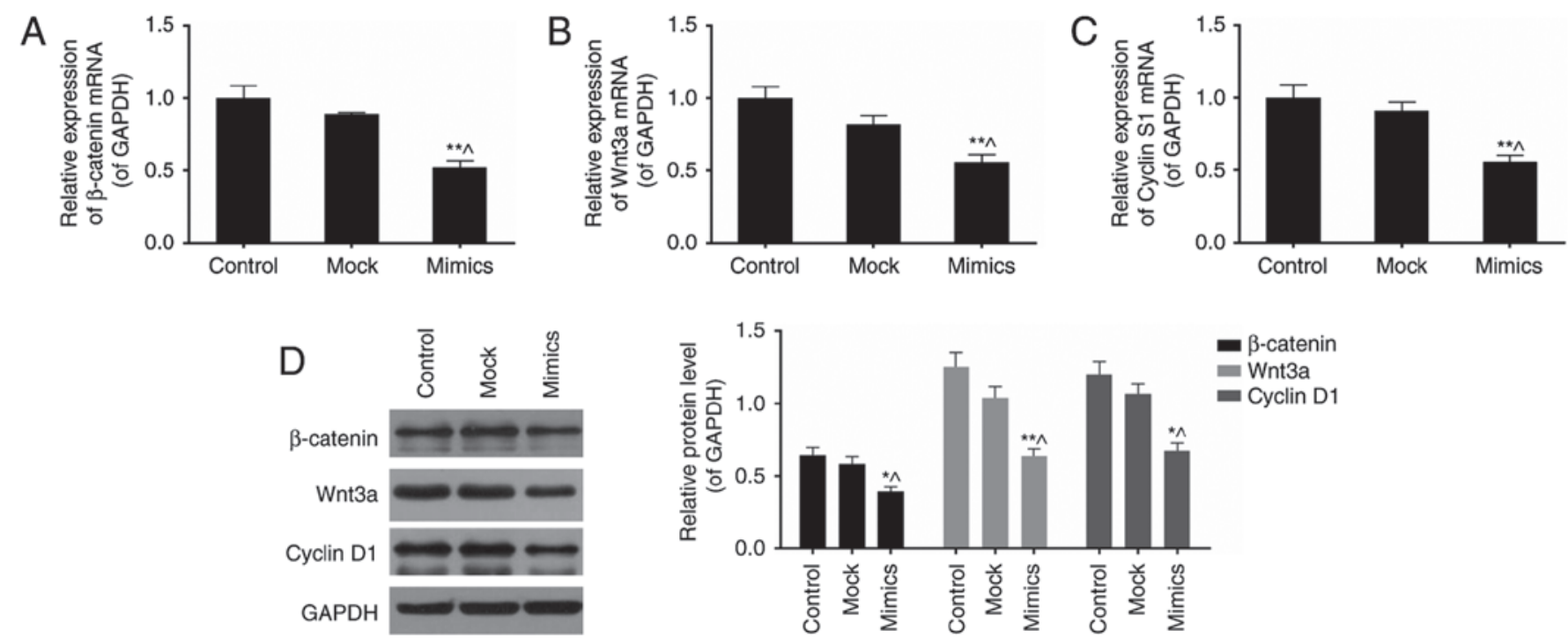

Figure 4. miR-377 overexpression inhibits Wnt/ $\beta$-catenin signaling pathway. Ectopic miR-377 expression inhibited the mRNA levels of (A) $\beta$-catenin, (B) Wnt3a and (C) cyclin D1 and (D) protein levels of $\beta$-catenin, Wnt3a and cyclin D1 were reduced in miR-377 overexpression cells. Data are expressed as the mean \pm standard deviation from three independent experiments. ${ }^{*} \mathrm{P}<0.05$ and ${ }^{* *} \mathrm{P}<0.01$ vs. control, ${ }^{\wedge} \mathrm{P}<0.05$ vs. mock. CUL4, cullin $4 \mathrm{~A}$; miR, microRNA.

the effects of miR-377 on ovarian cancer in vitro. The effect of expression of the miR-377 mimics on the expression level of CUL4A was subsequently assessed using RT-qPCR and western blotting (Fig. 3A-C). The miR-377 expression levels in the mimics group exhibited an almost three-fold increase compared with normal SKOV3 cells ( $\mathrm{P}<0.05$; Fig. $3 \mathrm{~A})$. Overexpression of miR-377 downregulated CUL4A mRNA and protein expression levels. As presented in Fig. 3C, the expression of miR-377 mimics resulted in an approximately $20 \%$ decrease in CUL4A protein expression compared with expression of the mock.

miR-377 mimics attenuate viability, migration and invasion of SKOV3 cells. The effects of miR-377 mimics on biological processes in SKOV3 cells were next investigated, including cell viability, migration, and invasion (Fig. 3D-F). In the miR-377 mimic group, cell viability was markedly inhibited by the high level of miR-377, compared with normal cell group $(\mathrm{P}<0.05$; Fig. 3D). Furthermore, with miR-377 overexpression, migration and invasion rates were attenuated $(\mathrm{P}<0.01$; Fig. $3 \mathrm{E}$ and $\mathrm{F})$. These results implied the important role of miR-377 in ovarian cancer.

miR-377 mimics inhibit Wnt/ $\beta$-catenin signaling pathway in SKOV3 cells. $\beta$-catenin, Wnt3a, and cyclin D1 are three key components in the $\mathrm{Wnt} / \beta$-catenin signaling pathway (26). To investigate the effects of miR-377 on this signalling pathway, expression levels of these three genes were assessed in normal and miR-377 mimics conditions (Fig. 4A-D). As a result, overexpression of miR-377 downregulated the expression of $\beta$-catenin, Wnt3a, and cyclin D1 $(\mathrm{P}<0.05)$.

miR-377 mimics affect the expression of MMP-2, MMP-9, MTA1 and TIMP2 in SKOV3 cells. Subsequently, the influence of miR-377 overexpression on tumor metastasis-associated genes including MMP-2 and 9, MTA1 and TIMP2 was assessed. MMPs and TIMPs serve important roles in extracellular matrix turnover (27). MTA1, a member of MTAs family, is an integral component of the nucleosome remodeling and histone deacetylation complexes (28). It has been reported to be highly expressed in metastatic cells compared with non-metastatic ones (29). Expression levels of MMP-2, MMP-9, MTA1 and TIMP2 were influenced by miR-377 overexpression (Fig. 5A-E). Cells transfected with the miR-377 overexpression construct expressed lower levels of MMP-2, MMP-9, and MTA1, however increased levels of TIMP2 $(\mathrm{P}<0.05)$.

\section{Discussion}

The expression of miR-377 is silenced in a number of human malignancies, which has been verified in previous studies (6-10). In fact, the large miRNA cluster on chromosome $14 q 32$ including miR-377 is termed as 'the largest miRNA tumour suppressor cluster' (9). The present analysis identified a total of 52 target genes of miR-377, and demonstrated that these genes were enriched in primary functions of regulation of gene expression, cell proliferation, and signal transduction. Aberrant expression of miR-377 in the ovarian cell line SKOV3 reduced cell viability, and resulted in inhibition of migration and invasion of the cancer cells, which suggested that miR-377 is likely to function as a suppressor in ovarian cancer.

There is a general lack of information regarding target genes of miR-377. A previous study demonstrated that miR-377 targets frizzled class receptor 4, which is required for epithelial-mesenchymal transition (EMT) and metastasis in prostate cancer cells (30). miR-377 has additionally been demonstrated to target cyclin dependant kinase 6 and E2F transcription factor 3 (31). However, previously it was unknown if miR-377 targeted CUL4A .

It was demonstrated that EMT is an essential process for the metastasis of cancer cells (32-34). Through EMT, cancer cells obtain stronger capability to move and migrate into the circulatory system via the extracellular matrix and basement membrane of blood vessels, and form secondary metastases as a consequence $(35,36)$. A key factor which 
A
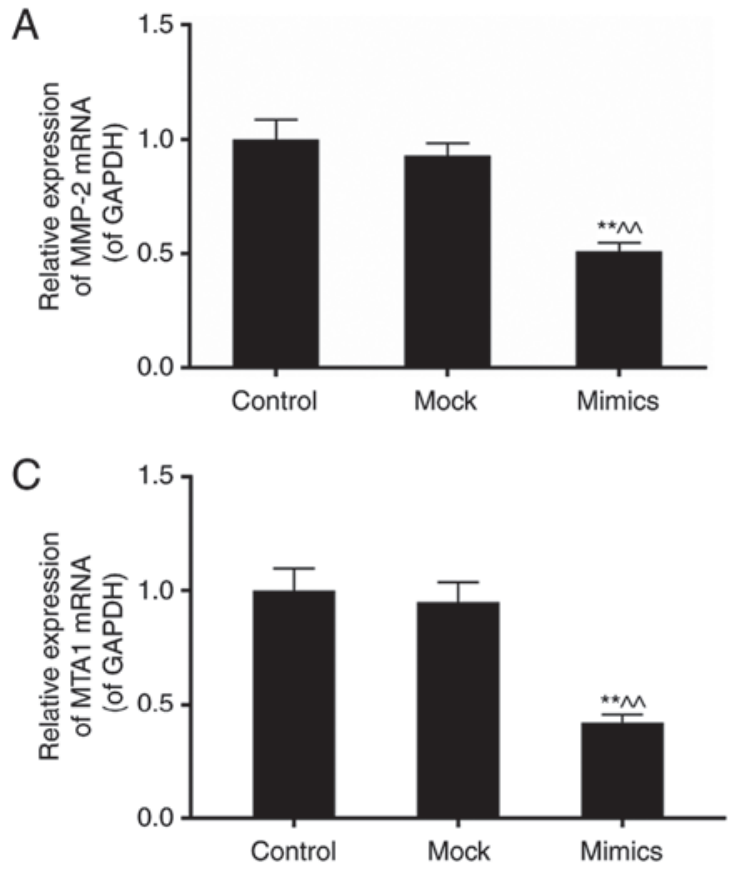
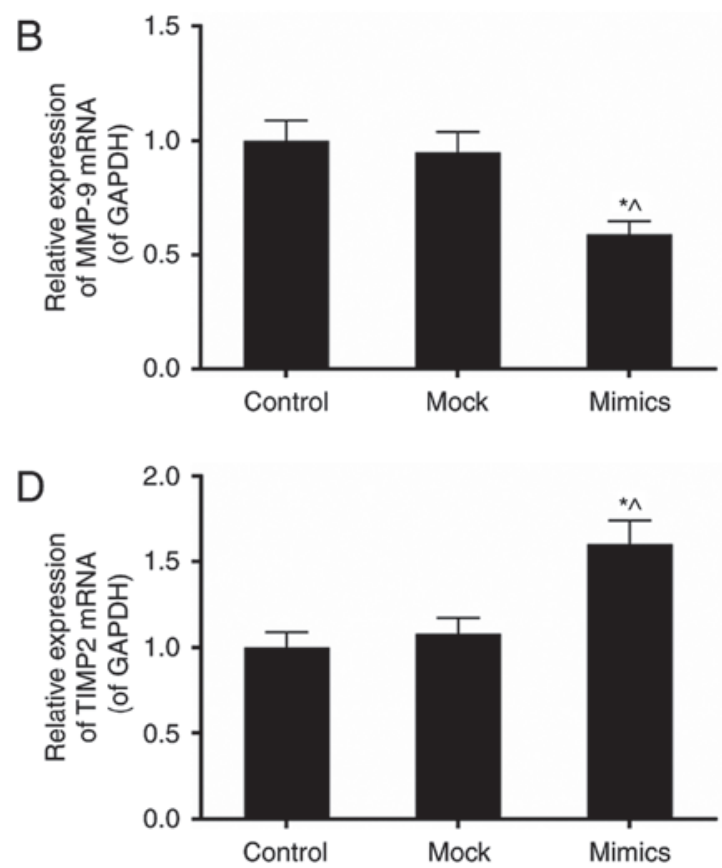

$\mathrm{E}$
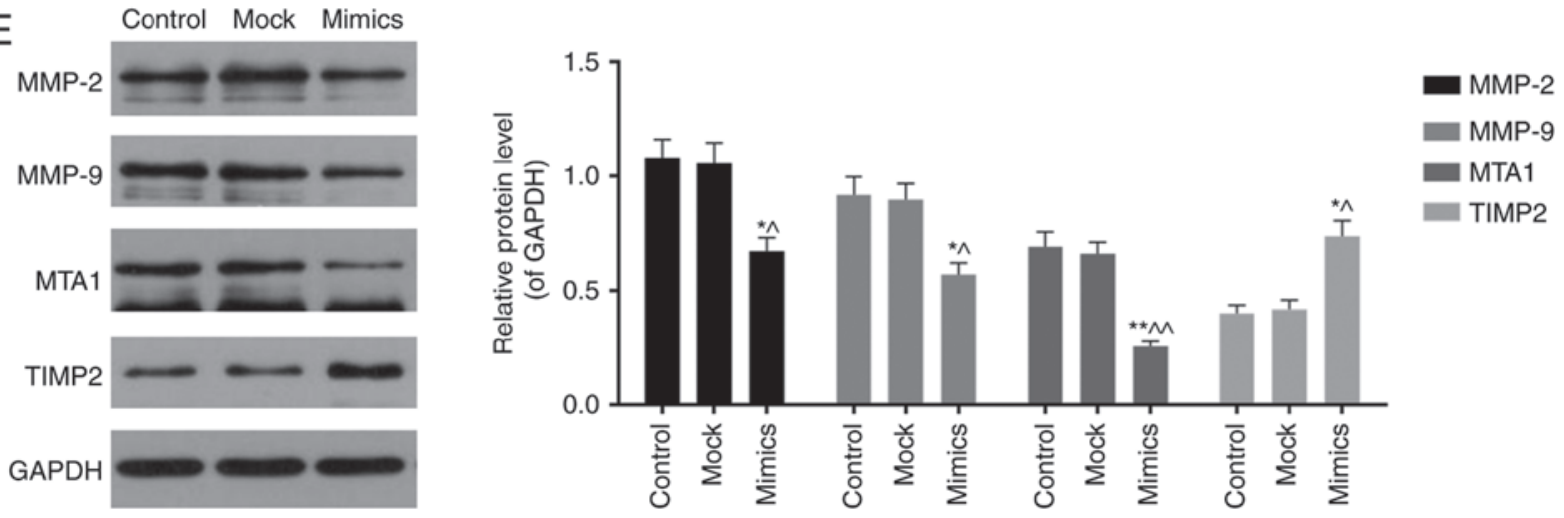

Figure 5. miR-377 overexpression influences the expression of MMP-2, MMP-9, MTA1 and TIMP2. Aberrant miR-377 level downregulated the expression of (A) MMP-2, (B) MMP-9 and (C) MTA1 mRNA, however upregulated (D) TIMP2 mRNA expression levels. (E) MMP-2, MMP-9 and MTA1 protein expression levels were decreased whereas TIMP2 protein expression was elevated in the miR-377 mimics group. Data are expressed as the mean \pm standard deviation from three independent experiments. ${ }^{*} \mathrm{P}<0.05$ and ${ }^{* * *} \mathrm{P}<0.01$ vs. control, ${ }^{\wedge} \mathrm{P}<0.05$ and ${ }^{\wedge} \mathrm{P}<0.01$ vs. mock. MTA, metastasis-associated protein; miR, microRNA.; MMP, matrix metalloproteinase; TIMP, metallopeptidase inhibitor.

regulates the occurrence of EMT in ovarian cancer may be not only an important biomarker of prognostic prediction of ovarian cancer, however also an important target in further studies for intervention treatments to more effectively inhibit or interdict metastasis of ovarian cancer. Ubiquitin ligase E3, which is classified into two categories, termed, ring-finger E3 ubiquitin ligase family and homologous to E6AP C-terminus (HECT) ubiquitin ligase family, according to the difference in transfer methods of ubiquitin, serves a role in ubiquitination-mediated degradation of proteins $(19,37,38)$. Belonging to the cullin-ringbased E3-ligases (CRLs), a principal part of the ring-finger E3 ubiquitin ligase family, CUL4A was first identified in breast cancer and its amplification is strongly associated with tumorigenesis and tumour migration of several cancers $(39,40)$. CUL4A, which was demonstrated to be overexpressed in ovarian cancer tissues and cell lines in the present study, is a direct target of miR-377, and its activity is regulated by miR-377. The present study demonstrated that the decrease in CUL4A protein levels, which were detected following overexpression of miR-377 resulted in inhibition of viability, migration, and invasion of SKOV3 cells.

A number of signal transduction pathways, including transforming growth factor- $\beta$, mitogen activated protein kinase, Notch and Wnt, participate in the process of EMT of tumour cells (26). The Wnt signaling pathway transmits signals from the cell surface into the cell nucleus by secreting Wnt signalling proteins, transmembrane receptor proteins, and other intracellular proteins (41). The canonical Wnt signaling pathway, also named $\mathrm{Wnt} / \beta$-catenin signaling pathway, serves a vital role in proliferation, differentiation, movement, and morphology of numerous cells (42-44). In the presence of Wnt signalling, Wnt proteins combine with the cell surface receptor Frizzled and members of the low-density lipoprotein receptor-related protein (LRP) family, LRP-5, -6 to activate intracellular dishevelled protein, inhibit phosphorylation of $\beta$-catenin, and protect intracytoplasmic unphosphorylated $\beta$-catenin from degradation via the ubiquitin-proteasome system. $\beta$-catenins in the cytoplasm gather and shift toward 
the cell nucleus so as to interact with the lymphoid enhancer factor/T cell factor to activate the transcription of target genes, including cyclin D1 and c-myc. The protein complex of $\beta$-catenin/E-cadherin combines with the actin cytoskeleton to reduce cell-cell adhesion and induce the EMT process of tumours, which strengthens the migration and invasion abilities of tumour cells (45-49).

In the Wnt/ $\beta$-catenin signaling pathway, Wnt 3 , a secretory protein of the pathway, is the promoter, and $\beta$-catenin, an important regulatory factor that conducts signals from the cell membrane or cytoplasm to the cell nucleus, is the executor of the regulatory function on its downstream targets. Cyclin D1, one of its targets, is a key intranuclear transcription factor that regulates the cell cycle (50). The present study demonstrated that aberrant miR-377 expression, attenuated the mRNA and protein levels of $\beta$-catenin, Wnt3a, and cyclin D1, which indicated the reduced activation of the Wnt/ $\beta$-catenin signaling pathway by miR-377 mimics. The results of the present study suggested that miR-377 reduces the migratory ability of SKOV3 cells, potentially by inhibiting the EMT process via the Wnt/ $\beta$-catenin signalling pathway.

MMP2, together with MMP9, is able to degrade type IV collagen, and degradation of the basement membrane allows cancer cells to migrate out of the tumour, resulting in metastasis (51). MTA1 suppresses the expression of numerous tumour suppressor genes contributing to cell migration and invasion (52). In the present study, it was demonstrated that the expression levels of MMP-2, MMP-9, MTA1, and TIMP2 were significantly influenced by miR-377 overexpression at the mRNA and protein levels. Cells transfected with the miR-377 overexpression construct expressed lower levels of MMP-2, MMP-9, and MTA1, however increased levels of TIMP2, which suggested that miR-377 is necessary for attenuating migration-associated protein expression.

In conclusion, the results of the present study suggested that miR-377 acted as a negative regulator of CUL4A, which resulted in reduced cancer cell viability and migration in an ovarian cancer cell line. It was then hypothesized that downregulation of miR-377 in ovarian cancer may promote tumorigenesis and metastasis through activation of CUL4A expression, however further in vitro and in vivo research is required to verify this.

\section{Acknowledgements}

Not applicable.

\section{Funding}

No funding was received.

\section{Availability of data and materials}

The analysed data sets generated during the study are available from the corresponding author on reasonable request.

\section{Authors' contributions}

RY and YC conceived and designed the study. XD analyzed and interpreted the patient data regarding the relationship of
miR-377 and CUL4A expression in ovarian cancer tissues. LC and XW performed the cell experiments to investigate the role of miR-377 in metastatic capability regulation. RY was a major contributor in writing the manuscript. All authors read and approved the final manuscript.

\section{Ethics approval and consent to participate}

The present study was approved by the ethics committee of the Third Affiliated Hospital of Wenzhou Medical University (Wenzhou, China). Written informed consent was obtained.

\section{Consent for publication}

Not applicable.

\section{Competing interests}

The authors declare that they have no competing interests.

\section{References}

1. Siegel RL, Miller KD and Jemal A: Cancer statistics, 2016. CA Cancer J Clin 66: 7-30, 2016.

2. Ozols RF, Bundy BN, Greer BE, Fowler JM, Clarke-Pearson D, Burger RA, Mannel RS, DeGeest K, Hartenbach EM and Baergen R; Gynecologic Oncology Group: Phase III trial of carboplatin and paclitaxel compared with cisplatin and paclitaxel in patients with optimally resected stage III ovarian cancer: A Gynecologic Oncology Group study. J Clin Oncol 21: 3194-3200, 2003.

3. Smith HJ, Straughn JM, Buchsbaum DJ and Arend RC: Epigenetic therapy for the treatment of epithelial ovarian cancer: A clinical review. Gynecol Oncol Rep 20: 81-86, 2017.

4. Armstrong DK, Bundy B, Wenzel L, Huang HQ, Baergen R, Lele S, Copeland LJ, Walker JL and Burger RA; Gynecologic Oncology Group: Intraperitoneal cisplatin and paclitaxel in ovarian cancer. N Engl J Med 354: 34-43, 2006.

5. Chambers AF, Groom AC and MacDonald IC: Dissemination and growth of cancer cells in metastatic sites. Nat Rev Cancer 2: 563-572, 2002.

6. Costa FF, Bischof JM, Vanin EF, Lulla RR, Wang M, Sredni ST, Rajaram V, Bonaldo Mde F, Wang D, Goldman S, et al: Identification of microRNAs as potential prognostic markers in ependymoma. PLoS One 6: e25114, 2011.

7. Gattolliat CH, Thomas L, Ciafre SA, Meurice G, Le Teuff G, Job B, Richon C, Combaret V, Dessen P, Valteau-Couanet D, et al: Expression of miR-487b and miR-410 encoded by $14 \mathrm{q} 32.31$ locus is a prognostic marker in neuroblastoma. Br J Cancer 105: 1352-1361, 2011.

8. Haller F, von Heydebreck A, Zhang JD, Gunawan B, Langer C, Ramadori G, Wiemann S and Sahin O: Localization- and mutation-dependent microRNA (miRNA) expression signatures in gastrointestinal stromal tumours (GISTs), with a cluster of co-expressed miRNAs located at 14q32.31. J Pathol 220: 71-86, 2010.

9. Lavon I, Zrihan D, Granit A, Einstein O, Fainstein N, Cohen MA, Cohen MA, Zelikovitch B, Shoshan Y, Spektor S, et al: Gliomas display a microRNA expression profile reminiscent of neural precursor cells. Neuro Oncol 12: 422-433, 2010.

10. Thayanithy V, Sarver AL, Kartha RV, Li L, Angstadt AY, Breen M, Steer CJ, Modiano JF and Subramanian S: Perturbation of $14 \mathrm{q} 32$ miRNAs-cMYC gene network in osteosarcoma. Bone 50: 171-181, 2012.

11. Vasudevan S, Tong Y and Steitz JA: Switching from repression to activation: microRNAs can up-regulate translation. Science 318: 1931-1934, 2007.

12. Gong J, Zhang JP, Li B, Zeng C, You K, Chen MX, Yuan Y and Zhuang SM: MicroRNA-125b promotes apoptosis by regulating the expression of Mcl-1, Bcl-w and IL-6R. Oncogene 32: 3071-3079, 2013

13. Henke JI, Goergen D, Zheng J, Song Y, Schüttler CG, Fehr C, Jünemann C and Niepmann M: microRNA-122 stimulates translation of hepatitis C virus RNA. EMBO J 27: 3300-3310, 2008. 
14. Banelli B, Forlani A, Allemanni G, Morabito A, Pistillo MP and Romani M: MicroRNA in glioblastoma: An overview. Int J Genomics 2017: 7639084, 2017.

15. Honardoost M and Rad SMAH: Triangle of AKT2, miRNA, and tumorigenesis in different cancers. Appl Biochem Biotechnol, 2017 (Epub ahead of print).

16. Slaby O, Laga $\mathrm{R}$ and Sedlacek O: Therapeutic targeting of non-coding RNAs in cancer. Biochem J 474: 4219-4251, 2017.

17. Wu N, Zhao X, Liu M, Liu H, Yao W, Zhang Y, Cao S and Lin X: Role of microRNA-26b in glioma development and its mediated regulation on EphA2. PLoS One 6: e16264, 2011.

18. Kuninty PR, Schnittert J, Storm G and Prakash J: MicroRNA targeting to modulate tumor microenvironment. Front Oncol 6 : 3, 2016.

19. Sarikas A, Hartmann T and Pan ZQ: The cullin protein family. Genome Biol 12: 220, 2011

20. Jackson S and Xiong Y: CRL4s: The CUL4-RING E3 ubiquitin ligases. Trends Biochem Sci 34: 562-570, 2009.

21. Chen X, Zhang Y, Douglas L and Zhou P: UV-damaged DNA-binding proteins are targets of CUL-4A-mediated ubiquitination and degradation. J Biol Chem 276: 48175-48182, 2001.

22. Gupta A, Yang LX and Chen Lc: Study of the G2/M cell cycle checkpoint in irradiated mammary epithelial cells overexpressing Cul-4A gene. Int J Radiat Oncol Biol Phys 52: 822-830, 2002.

23. Livak KJ and Schmittgen TD: Analysis of relative gene expression data using real-time quantitative PCR and the 2(-Delta Delta C(T)) method. Methods 25: 402-408, 2001

24. Birner P, Schoppmann A, Schindl M, Dinhof C, Jesch B, Berghoff AS and Schoppmann SF: Human homologue for Caenorhabditis elegans CUL-4 protein overexpression is associated with malignant potential of epithelial ovarian tumours and poor outcome in carcinoma. J Clin Pathol 65: 507-511, 2012.

25. Beckman JD, Chen C, Nguyen J, Thayanithy V, Subramanian S, Steer CJ and Vercellotti GM: Regulation of heme oxygenase-1 protein expression by miR-377 in combination with miR-217. J Biol Chem 286: 3194-3202, 2011.

26. Savagner P: The epithelial-mesenchymal transition (EMT) phenomenon. Ann Oncol 21 (Suppl 7): vii89-vii92, 2010

27. Brun JL, Cortez A, Lesieur B, Uzan S, Rouzier R and Daraï E: Expression of MMP-2, -7, -9, MT1-MMP and TIMP-1 and -2 has no prognostic relevance in patients with advanced epithelial ovarian cancer. Oncol Rep 27: 1049-1057, 2012.

28. Malisetty VL, Penugurti V, Panta P, Chitta SK and Manavathi B MTA1 expression in human cancers-Clinical and pharmacological significance. Biomed Pharmacother 95: 956-964, 2017.

29. Xue Y, Wong J, Moreno GT, Young MK, Côté J and Wang W: NURD, a novel complex with both ATP-dependent chromatin-remodeling and histone deacetylase activities. Mol Cell 2 : 851-861, 1998.

30. Formosa A, Markert EK, Lena AM, Italiano D, Finazzi-Agro E, Levine AJ, Bernardini S, Garabadgiu AV, Melino G and Candi E: MicroRNAs, miR-154, miR-299-5p, miR-376a, miR-376c miR-377, miR-381, miR-487b, miR-485-3p, miR-495 and miR-654-3p, mapped to the $14 \mathrm{q} 32.31$ locus, regulate proliferation, apoptosis, migration and invasion in metastatic prostate cancer cells. Oncogene 33: 5173-5182, 2014.

31. Zehavi L, Schayek H, Jacob-Hirsch J, Sidi Y, Leibowitz-Amit R and Avni D: miR-377 targets E2F3 and alters the NF-kB signaling pathway through MAP3K7 in malignant melanoma. Mol Cancer 14: 68, 2015.

32. Sabe H: Cancer early dissemination: Cancerous epithelialmesenchymal transdifferentiation and transforming growth factor $\beta$ signalling. J Biochem 149: 633-639, 2011.

33. Micalizzi DS, Farabaugh SM and Ford HL: Epithelialmesenchymal transition in cancer: Parallels between normal development and tumor progression. J Mammary Gland Biol Neoplasia 15: 117-134, 2010.
34. Taylor MA, Parvani JG and Schiemann WP: The pathophysiology of epithelial-mesenchymal transition induced by transforming growth factor-beta in normal and malignant mammary epithelial cells. J Mammary Gland Biol Neoplasia 15: 169-190, 2010.

35. Thiery JP, Acloque H, Huang RY and Nieto MA: Epithelialmesenchymal transitions in development and disease. Cell 139: 871-890, 2009.

36. Chapman HA: Epithelial-mesenchymal interactions in pulmonary fibrosis. Ann Rev Physiol 73: 413-435, 2011.

37. Zhao Y and Sun Y: Cullin-RING Ligases as attractive anti-cancer targets. Curr Pharm Des 19: 3215-3225, 2013.

38. Jia L and Sun Y: SCF E3 ubiquitin ligases as anticancer targets. Curr Cancer Drug Targets 11: 347-356, 2011.

39. Chen LC, Manjeshwar S, Lu Y, Moore D, Ljung BM, Kuo WL, Dairkee SH, Wernick M, Collins C and Smith HS: The human homologue for the Caenorhabditis elegans cul-4 gene is amplified and overexpressed in primary breast cancers. Cancer Res 58: 3677-3683, 1998.

40. Schindl M, Gnant M, Schoppmann SF, Horvat R and Birner P: Overexpression of thehumanhomologue for Caenorhabditiselegans cul-4 gene is associated with poor outcome in node-negative breast cancer. Anticancer Res 27: 949-952, 2007.

41. Toda H, Boku S, Nakagawa S, Inoue T, Kato A, Takamura N, Song N, Nibuya M, Koyama T and Kusumi I: Maternal separation enhances conditioned fear and decreases the mRNA levels of the neurotensin receptor 1 gene with hypermethylation of this gene in the rat amygdala. PLoS One 9: e97421, 2014.

42. Moon RT, Bowerman B, Boutros M and Perrimon N: The promise and perils of Wnt signaling through beta-catenin. Science 296: 1644-1646, 2002.

43. Moon RT, Kohn AD, De Ferrari GV and Kaykas A: WNT and beta-catenin signalling: Diseases and therapies. Nat Rev Genet 5: 691-701, 2004.

44. Zhang L, Yang X, Yang S and Zhang J: The Wnt/B-catenin signaling pathway in the adult neurogenesis. Eur J Neurosci 33: $1-8,2011$.

45. Nelson WJ and Nusse R: Convergence of Wnt, beta-catenin, and cadherin pathways. Science 303: 1483-1487, 2004

46. Toledo EM, Colombres M and Inestrosa NC: Wnt signaling in neuroprotection and stem cell differentiation. Prog Neurobiol 86: 281-296, 2008

47. Liu F and Millar SE: Wnt/beta-catenin signaling in oral tissue development and disease. J Dent Res 89: 318-330, 2010.

48. Michaelidis TM and Lie DC: Wnt signaling and neural stem cells: Caught in the Wnt web. Cell Tissue Res 331: 193-210, 2008.

49. Liu J, Wang Z, Tang J, Tang R, Shan X, Zhang W, Chen Q, Zhou F, Chen K, Huang A, et al: Hepatitis $C$ virus core protein activates Wnt/ $\beta$-catenin signaling through multiple regulation of upstream molecules in the SMMC-7721 cell line. Arch Virol 156: 1013-1023, 2011.

50. Vallée A, Lecarpentier Y, Guillevin R and Vallee JN: Thermodynamics in gliomas: Interactions between the Canonical WNT/Beta-catenin pathway and PPAR Gamma. Front Physiol 8: 352,2017

51. Mook OR, Frederiks WM and Van Noorden CJ: The role of gelatinases in colorectal cancer progression and metastasis. Biochim Biophys Acta 1705: 69-89, 2004.

52. Zhang Y and Wang XF: Post-transcriptional regulation of MTA family by microRNAs in the context of cancer. Cancer Metastasis Rev 33: 1011-1016, 2014.

This work is licensed under a Creative Commons Attribution-NonCommercial-NoDerivatives 4.0 International (CC BY-NC-ND 4.0) License. 